\title{
APUNTES SOCIOLINGÜÍSTICOS SOBRE LA PRESENCIA DE ARGENTINISMOS EN EL LÉXICO DEL ESPAÑOL DE CHILE
}

SOME SOCIOLINGUISTIC NOTES ON THE PRESENCE OF ARGENTINISMS IN THE LEXICON OF CHILEAN SPANISH

\section{GASTÓN SALAMANCA ${ }^{1}$}

\section{RESUMEN}

En este artículo se reflexiona sobre la influencia que la variante del español hablada en Argentina ejerce en el léxico del español de Chile. Dos ejes articulan su contenido: la aplicación del concepto sociolingüístico de prestigio encubierto, para describir el valor que el chilenohablante otorga a la variante hablada en Argentina, y lo que el autor denomina permeabilidad asimétrica, respecto de la relación que se establece entre ambas variantes. Se especula que la tendencia a la argentinización cultural en general y lingüística en particular se mantendrá y tenderá a consolidarse.

Palabras clave: Sociolingüística, español de Chile, argentinismos.

\section{ABSTRACT}

The influence of Argentine Spanish on the lexicon of Chilean Spanish is examined in this article. Its content is presented via two axes: the application of the sociolinguistic concept of hidden prestige, for the purpose of describing the value that the speaker of Chilean Spanish gives to the dialect spoken in Argentina; and what the author calls asymmetrical permeability with respect to the relationship that is created between the two dialects. It is proposed that the tendency towards the Argentinization of the culture generally, and particularly of the language, will continue and tend to become consolidated.

Keywords: Sociolinguistics, Chilean Spanish, Argentinisms.

Recibido: 23.04.2009. Aprobado: 12.06.2010.

${ }^{1}$ Doctor en Lingüística. Profesor de la Facultad de Humanidades y Arte, Universidad de Concepción. Concepción, Chile. E-mail: gaston.salamanca@gmail.com 


\section{INTRODUCCIÓN}

T OS ESTUDIOS sobre el prestigio y estigmatización que asignan los hablantes del castellano de Chile a otras lenguas o variantes dialectales del español han podido establecer que los hablantes de esta variedad dialectal ${ }^{2}$ son extremadamente críticos con aquellos usos que estiman no prestigiosos. Así, por ejemplo, siguiendo a Salas (1996: 25), los hablantes del castellano de Chile no dudan en considerar como verdaderas lenguas al inglés o el alemán, pero dudarían o -lisa y llanamente- descartarían la posibilidad de asignarle este estatus a lenguas indígenas como el mapuche o el aymara.

Este prestigio o estigmatización se correlaciona de manera directa con la presencia de préstamos de una lengua o variante de ella en otra. Así, por ejemplo, en relación con la posible influencia del mapudungun en el léxico del español de Chile, el mismo Salas señala que "[...] es cuantitativa y cualitativamente mínima: hay pocos mapuchismos, y casi todos ellos son de frecuencia baja, de circulación restringida, esporádicos y ocasionales, y más bien triviales desde el punto de vista cultural" (Salas, 1992: 17).

Situación distinta es la que exhibe una lengua como el inglés, lo cual se ha traducido, de acuerdo con Sáez (1999: 18), en la incorporación de “[...] un aluvión de anglicismos [...], muchos de los cuales se instalan en la lengua común". De hecho, este mismo autor constata más de tres mil voces procedentes de esta lengua, añadiendo que se agregan entre diez a quince a la semana. Por supuesto, todo esto es evidencia clara de una lengua que se estima prestigiosa.

Por otra parte, en la tesis que dirigí sobre la valoración subjetiva de las vocales (anteriorizadas y posteriorizadas) del español de Chile (Salamanca y Valverde, 2009), pudimos confirmar la perspectiva de Valdivieso en cuanto a que " $[. .$.$] la lengua, como muchos otros fenómenos sociales, está some-$ tida a un proceso constante de valoración social" (Valdivieso, 1983: 137). En efecto, en la tesis mencionada pudimos establecer con claridad que las vocales anteriorizadas se asocian con sujetos señalados como flaites, esto es, pertenecientes a un estrato sociocultural bajo, y las vocales posteriorizadas se asocian con sujetos señalados como cuicos, esto es, pertenecientes a un estrato sociocultural alto.

Algo particularmente interesante de la investigación mencionada es que hubo dos casos en que todas las respuestas fueron en una misma dirección:

\footnotetext{
${ }^{2}$ Dialecto es usado aquí en un sentido técnico, esto es, como la manifestación de una lengua en un espacio geográfico determinado y no con el sentido peyorativo que se le suele asignar en el lenguaje cotidiano.
} 
se vinculaban con el estrato sociocultural bajo, lo que confirma la idea de que el hablante del castellano de Chile es particularmente sensible al habla de este estrato. Esto es más llamativo si se considera que, en términos socioeconómicos, los sujetos encuestados estaban cercanos a los hablantes cuyos usos lingüísticos juzgaban ${ }^{3}$. Decimos que esto tiene un componente sorpresivo porque se podría esperar que los sujetos que pertenecen a un estrato sociocultural determinado tuvieran escasa consciencia del nivel de estigmatización que ostentan los usos que a ellos les son asignados.

Las reflexiones que presentamos en el presente artículo se traslapan parcialmente con las observaciones contenidas en los párrafos anteriores, por cuanto tienen como foco el español de Chile; pero no se refieren a alguna de sus variantes diatópicas, diafásicas o diastráticas, sino a la influencia que otra variante del español -el español hablado en Argentina- tiene sobre él.

Hasta donde sabemos, no existe una línea de investigación consolidada ni en ciernes respecto de este tópico, lo que catapulta este artículo como un aporte que puede desplegar una serie de investigaciones desde distintas perspectivas.

\section{PERCEPCIÓN FOLK, ASIMILACIÓN SELECTIVA Y PRESTIGIO ENCUBIERTO}

Un rasgo sociolingüístico que se atribuye a los chilenohablantes es una notable facilidad para asimilar formas lingüísticas de otras variantes del español. Esta observación, que es comprobable empíricamente ${ }^{4}$, sin embargo, no aplica de manera homogénea, sino selectiva, pues se produce respecto de aquellas variantes dialectales que se estiman prestigiosas, sea este prestigio explícito o encubierto 5 .

Así, por ejemplo, a pesar de que la presencia de peruanos en nuestro país es relativamente importante ${ }^{6}$ y que dicha presencia se concentra en la capital, la variante dialectal del español que éstos utilizan no es una forma de habla que el chilenohablante considere prestigiosa. En efecto, no obstante que

\footnotetext{
${ }^{3}$ Sector medio-bajo de la comuna de Penco.

${ }^{4}$ Pensemos, por ejemplo, en la facilidad con que los futbolistas chilenos radicados por corto o largo tiempo en países como México, Argentina o España asimilan las variantes lingüísticas de estos países.

${ }^{5}$ Para el concepto de prestigio encubierto, véase Silva-Corvalán (2001: 99).

${ }^{6}$ De acuerdo con el estudio de Riquelme y Alarcón (2008: 301): “[...] según estimaciones del Ministerio del Interior, la población peruana es la de mayor presencia en nuestro país, con un $26 \%$, seguida de la argentina $-22 \%-$ y la boliviana con un $6 \%$ [...]”.
} 
muchos chilenos reconocen en los peruanos a "gente que habla bien" -entre otras cosas, "porque pronuncian todas las eses"- no se sentirían halagados si se dijera de ellos que hablan como peruanos. Es lo que podríamos denominar, en términos del metalenguaje sociolingüístico, un desprestigio encubierto; una ponderación positiva que, dicho en chileno, es "de la boca hacia afuera”.

En el otro extremo, si consideramos el español de España, advertiremos que respecto de él existe un prestigio que se evidencia no sólo a nivel del discurso, sino también en las actitudes y reacciones asociadas con él. Este prestigio se explicita en declaraciones tales como "allí se habla bien" o "allí se habla el verdadero español"7; pero también en la alta permeabilidad al léxico y/o entonación cuando se permanece algún tiempo en ese país. Claramente, éste es un caso de prestigio explícito.

Una relación tan interesante como las descritas es la que se establece entre el castellano de Chile y el castellano de Argentina, uno de cuyos rasgos más interesantes es el desfase que se produce entre lo que el chilenohablante verbaliza sobre "lo argentino" y la facilidad con que ingresan al español coloquial chileno expresiones lingüísticas provenientes de la variante transandina.

No parece contrafactual, en efecto, sostener que a nivel discursivo la imagen que se configura en Chile respecto de "lo argentino" es, en general, desmejorada, lo que se verifica, por ejemplo, en las reacciones de reprobación de que son objetos quienes pertenecen a esta nacionalidad cuando son nombrados en instancias públicas como festivales, presentaciones deportivas, etc. Todo indicaría, entonces, que el español hablado en Argentina no constituiría un referente lingüístico para los chilenos. Sin embargo, como veremos, la permeabilidad que se aprecia respecto de los giros lingüísticos usados en este país es significativa. A diferencia de los casos descritos en los párrafos precedentes, éste es un caso de prestigio encubierto.

Ahora, también es interesante advertir que esta permeabilidad no es recíproca, sino asimétrica. En efecto, el hecho de que los argentinos que se establecen en nuestro país, aun por muchos años, no pierdan su acento habla de una lealtad significativa de éstos a su variante del español. Nuevamente, el caso de los futbolistas es paradigmático, pues basta entrevistar a algunos de ellos que llevan avecindados algunos o muchos años en Chile para advertir que, en general, las características fonéticas, gramaticales y

\footnotetext{
${ }^{7}$ Incluso un lector de noticias del canal chileno con mayor cobertura nacional habla en esta variedad.
} 
léxicas del español hablado en este país no ha influido significativamente en sus hablas.

\section{ARGENTINISMOS EN EL LÉXICO DEL ESPAÑOL DE CHILE}

\subsection{Una presencia histórica ${ }^{8}$}

Hay argentinismos que se rastrean históricamente en el español de Chile. El origen de estos argentinismos, a su vez, está vinculado con el lunfardo ${ }^{9}$. Es el caso, entre muchos otros, de las palabras atorrante, mina, cafiche, facha y gil, las cuales tienen en Chile ligeros matices de significado/uso con respecto a sus variantes transandinas, pero en lo medular conservan sus semas y contextos de aplicación.

\section{a) Atorrante}

El significado que se le da a esta palabra en el Diccionario del lunfardo es:

Vago, ocioso, haragán//. Sujeto que no trabaja ni tiene domicilio; vive desafectado de sus semejantes, desaseado, sin el menor cuidado de su persona, y sin interés por integrarse a la vida de la sociedad (Espíndola, 2002: 40-41).

Por otro lado, el Diccionario de la Real Academia Española de la Lengua (en adelante, DRAE) confirma en sus dos primeras acepciones su distribución en Argentina (y Uruguay):

atorrante, ta. 1. adj. despect. Arg. y Ur. vago ( holgazán). U.t. c. s.

2. m. y f. despect. Arg. y Ur. Persona desfachatada, desvergonzada ${ }^{10}$

\footnotetext{
${ }^{8}$ Sobre el origen y extensión territorial de la mayoría de las palabras que incluimos aquí no existe una y sólo una opinión. Las fuentes que hemos estimado más confiables en este sentido son el Nuevo diccionario lunfardo (Gobello, 1999), el Diccionario del lunfardo (Espíndola, 2002) y el Diccionario de la Real Academia Española de la Lengua (Real Academia Española, 2009. Utilizamos la versión on line disponible en $<\mathrm{http} / / / \mathrm{www} \cdot$ rae.es $>$ ).

${ }^{9}$ Gobello (1999: 9) define el lunfardo como "un repertorio de términos traídos por la inmigración, durante la segunda mitad del siglo pasado y hasta el estallido de la primera gran guerra, y asumidos por el pueblo bajo de Buenos Aires, en cuyo discurso se mezclaban con otros de origen campesino, y quechuismos y lusismos que corrían ya en el habla popular, conformando un léxico que circula ahora en todos los niveles sociales de las 'repúblicas del Plata"'.

${ }^{10} \mathrm{En} \mathrm{http} / / /$ buscon.rae.es/draeI/SrvltConsulta?TIPO_BUS=3\&LEMA=atorrante
}

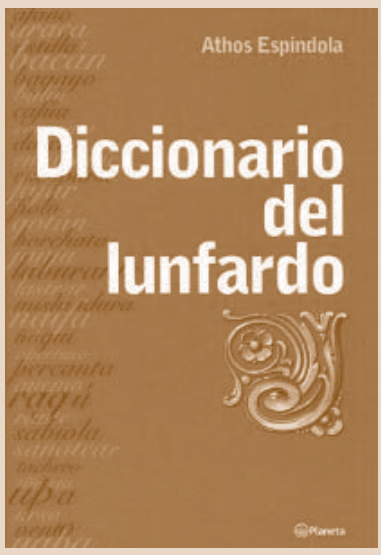


Nótese que este diccionario no menciona a Chile como país en el cual esta palabra es usada. Sin embargo, las acepciones recién señaladas coinciden con el significado que esta palabra posee en nuestro país ${ }^{11}$. Un titular del periódico chileno The Clinic y un posteo en uno de los foros del diario La Nación muestran la presencia de esta palabra en el español de Chile actual ${ }^{12}$ :

- Salmonix, la mascota más atorrante de todos los tiempos. Salmonix era la mascota de Deportes Puerto Montt ${ }^{13}$.

- El nacismo es una ideología foránea, no chilena, otra importación europea degenerada tendiente a destruir la idiosincracia chilena creando odio en la juventud. Por eso afirmo que el ATORRANTE no es chileno. No leo su basura ideológica europea y degenerada, porque YO SOY CHILENO $^{14}$.

En cuanto al origen de esta palabra, es interesante lo que consigna el Diccionario del lunfardo:

[...] ha ganado más consenso la versión que remite el caso a la época que se trajeron de Europa los grandes caños de hierro destinados a las obras sanitarias del Buenos Aires que crecía incesantemente. Estos caños, que llevaban impresos el nombre de su fabricante, A. Torrent, se dejaron depositados durante algún tiempo en las zonas aledañas al puerto de la ciudad y fueron aprovechados por los vagabundos como refugio y lugar donde dormir. Alguien, ingeniosamente, con el nombre de A. Torrent dio formación a la palabra atorrante para designar a esos individuos. (Espíndola, 2002: 41).

El mismo diccionario referido indica que en Argentina esta palabra comenzó a tener vigencia popular en los años inmediatamente anteriores a 1880 , fecha, sin duda, más precoz que aquella en que se comienza a rastrear su aparición en nuestro país.

\footnotetext{
${ }^{11}$ Aunque su pronunciación informal más difundida omite la vocal inicial, resultando torrante.

${ }^{12}$ Los ejemplos que aquí presentamos provienen en su mayoría de la prensa escrita para público masivo. Estimamos que este corpus es pertinente por dos razones: a) revela que una cantidad importante de chilenohablantes a lo menos entiende la terminología que aquí se utiliza (el público previsto como posible lector de estos escritos) y b) es, precisamente, en el habla popular donde se producen los cambios lingüísticos, pues la lengua formal tiene un marcado carácter conservador. El caso de la evolución del castellano desde el latín vulgar, pasando por las lenguas romances, es un buen ejemplo de lo anterior.

${ }^{13}$ En http://www.theclinic.cl/2009/06/19/salmonix-la-mascota-mas-atorrante-de-todos-lostiempos/

${ }_{14}$ En http://www.lanacion.cl/p4_lanacion/antialone.html?page=http://www.lanacion.cl/ p4_lanacion/foros/edic/port/565/10.html
} 
b) Mina

El significado que se le da a esta palabra en el Diccionario del lunfardo es:

Mujer, en general.// Querida. Salió de paseo con su mina.// Mujer que es pareja de un hombre (Espíndola, 2002: 325).

Por otro lado, el DRAE en una de sus acepciones confirma su distribución en Argentina (además de Bolivia y Uruguay):

11. f. Arg., Bol. y Ur., mujer ${ }^{15}$

Nuevamente, llama la atención que no se mencione a Chile como uno de los países donde se utiliza esta palabra. Sin embargo, salvo ligeros matices, este significado coincide con el que se le da en el castellano hablado en este país ${ }^{16}$. Así lo demuestran los siguientes ejemplos extraídos de un sitio que promociona un concurso en internet y un titular de un popular diario de circulación nacional, respectivamente:

- La Mina Más Rica de Morandé Con Compañía ${ }^{17}$

- "Nunca me he creído una mina rica". Marie Ann es finalista de uno de los concursos más importantes[... $]^{18}$

Con respecto al origen de esta palabra, el Diccionario del lunfardo señala que:

La etimología de esta voz ofrece diversas interpretaciones, desde quienes la derivan de mina como que la mujer así llamada era una mina de oro para su cafisho, siguiendo con aquellos que la remiten a un jergal. Ital., minna, mujer; o miniera, con la acepción de prostituta, hasta los que ven en el vocablo un lusitanismo por contracción del portugués menina (mulher nova, solteira e de maneiras delicadas). José Gobello la deriva del ital. Jergal mina, mujer, y señala que 'esta voz, que acumula en Buenos Aires 120 años de existencia y vigencia' tenía connotaciones lupanarias (Espíndola, 2002: 325).

Así, dado que esta palabra se vincula muy probablemente con el italiano

\footnotetext{
${ }^{15}$ En http://buscon.rae.es/draeI/SrvltConsulta?TIPO_BUS=3\&LEMA=mina

16 Tan productiva es esta palabra en Chile que es común derivar otras como minita, minoca, etc., introduciendo algunos matices afectivos o de otro orden.

${ }^{17}$ En http://www.antronio.com/f105/mina-mas-rica-de-morande-compania-446525/

${ }^{18}$ En http://www.lanacion.cl/prontus_noticias_v2/site/artic/20070920/pags/2007092019 1112.html
} 
y que su fecha de aparición en Argentina es anterior a su fecha de aparición en Chile, es posible sostener que su migración más probable se produjo desde ese país a Chile y no a la inversa.

\section{c) Cafiche}

(Cafisho)

El significado que se le da a esta palabra en el Diccionario del lunfardo es:

lunf. Rufián. Explotador de prostitutas.// sent. Fig. p. ext. Elegante, bien vestido (por lo atildado que eran en su vestir los cafishos). // p. ext. Refiriéndose a cosas: bien puesto, bien presentado, coqueto. (Espíndola, 2002: 93).

Por su parte, el DRAE señala:

cafiche.

1. m. despect. Chile. Proxeneta ${ }^{19}$

Nótese que, a diferencia de los casos anteriores, el DRAE sí menciona a Chile como país donde se usa esta palabra. Esto se puede confirmar con los siguientes titulares de la prensa chilena:

- Verdaderos trabajos de joyería realizó la prostituta Raquel Rodríguez (29) para engatusar y sacarles información vital a sus clientes de turno, con el propósito de que después su pareja y cafiche, Yuri Neira Bustamante (39), los extorsionara bajo amenaza de chupetearlos con sus familias o en sus pegas si no se ponían con un buen turro ${ }^{20}$.

- Re: Cuánto más dura la Marlen con el Cafiche Dueñas ${ }^{21}$.

Nótese también que el DRAE no menciona a Argentina como país donde se usa esta palabra. Sin embargo, como hemos establecido con la cita inicial del Diccionario del lunfardo, esta palabra tiene pleno uso en ese país. Más aún, como se observa en la siguiente cita, la conexión de esta palabra

\footnotetext{
${ }^{19}$ En http://buscon.rae.es/draeI/SrvltConsulta?TIPO_BUS=3\&LEMA=cafiche

${ }^{20}$ En http://www.lacuarta.cl/diario/2006/02/05/05.05.4a.CRO.RUCIA.html

${ }^{21}$ En http://www.antronio.com/f15/cuanto-mas-dura-marlen-cafiche-duenas-encuestatorobolun-226209/
} 
con el italiano es clara y, por lo tanto, su vínculo original con el español hablado en Argentina es mucho más plausible que con el español chileno:

[...] Italianismo, adaptación fonética del italiano stoccafisso, merluza o bacalao seco... De cómo stoccafisso vino a designar entre nosotros al proxeneta, es una historia interesante: en italiano se dice que un individuo parece un stoccafisso cuando es rígido y delgado y, evidentemente, el símil se aplicó a los rufianes de fines del siglo XIX por su andar tieso y duro. La comparación se convirtió, como sucede en muchos casos, en una metáfora, de modo que, en lugar de decirse Fulano parece un stoccafisso, se contrajo a Fulano es un stoccafisso. La deformación de la pronunciación italiana hizo el resto. Naturalmente que, en su país de origen, Italia, la palabra stoccafisso sólo se aplica al pez (Espíndola, 2002: 93. Las cursivas utilizadas en la primera palabra son nuestras).

\section{d) Facha}

El Diccionario del lunfardo señala:

p. Cara. Rostro. ¿Qué te pasa, que tenés esa facha? Me miró con facha de enojado.// p. ext. Pinta. Elegancia.// Tener facha. Tener pinta. Ser elegante. // Hacer facha. Hacer pinta. Lucirse. (Véase pinta) (Espíndola 2002: 212).

El DRAE respalda su difusión en Argentina (y Uruguay):

facho ${ }^{2}$, cha.

1. adj. despect. coloq. Arg. y Ur.

facha ${ }^{1}$.

(Del it. faccia).

1. f. coloq. Traza, figura, aspecto.

2. f. coloq. Mamarracho, adefesio. U. t. c. m.

3. f. Chile. Jactancia. ${ }^{22}$

Nótese que el DRAE menciona a Chile como un país donde esta palabra se utiliza. Sin embargo, el significado de "jactancia" que se le asigna no se condice con el uso más difundido en nuestro país. En efecto, tal como muestran los siguientes ejemplos extraídos de un popular sitio de internet y del diario de mayor circulación nacional (Las Últimas Noticias), el significado

${ }^{22}$ En http://buscon.rae.es/draeI/SrvltConsulta?TIPO_BUS=3\&LEMA=facha 
más difundido en Chile coincide con aquel que se le atribuye en Argentina y Uruguay:

- Madonna luce su mejor facha en campaña publicitaria ${ }^{23}$

- La cantante chilena que mata con su voz y su facha ${ }^{24}$

Nótese, además, que esta palabra, de acuerdo con la segunda entrada del $D R A E$, tiene su origen en el italiano. Esta opinión es compartida por el Diccionario del lunfardo, el cual señala: "Del ital. faccia, de igual sentido" (Espíndola, 2002: 212); de ahí que resulte plausible establecer su difusión desde Argentina a Chile y no lo contrario.

e) Gil

El Diccionario del lunfardo señala:

lunf. Tonto, ingenuo, otario. // Cartón cuadro vichenzo. Del esp. Fam. Gilí, lelo, que, a su vez, deriva del caló jil, con igual significado (Espíndola, 2002: 246).

El Nuevo diccionario lunfardo contiene una cita de Lugones (1879), donde ya aparece esta palabra: "En la estafa, el gil [sinónimo de otario] ve los objetos con que va a ser robado..." (Gobello, 1999: 129).

Por su parte, el DRAE confirma su difusión en Argentina (y Uruguay):

gil $^{2}$, la.

(De gilí).

1. adj. Arg. y Ur. Dicho de una persona: simple (incauta). U. t. c. s. ${ }^{25}$

Es interesante que el DRAE no contempla su uso en Chile. No obstante, los siguientes ejemplos extraídos de un diario popular chileno son elocuentes:

- Lola de 13 se fugó con gil que conoció por chat ${ }^{26}$

- Robo y violación le cargan a gil que jodió a prostis ${ }^{27}$

${ }^{23}$ En http://www.terra.cl/entretencion/index.cfm?id_cat=2471\&id_reg=1212401

${ }^{24}$ En http://www.lun.com/lunmobile/Pages/NewsDetailMobile. aspx?dt=2009-0724\&BodyId $=0 \&$ PaginaID $=8 \&$ NewsID $=5137 \&$ Name $=I 16 \&$ PagNum $=0 \&$ Return $=$ R\&SupplementId $=1$

${ }^{25} \mathrm{En} \mathrm{http://buscon}$. rae.es/draeI/SrvltConsulta?TIPO_BUS=3\&LEMA=gil

${ }^{26} \mathrm{En} \mathrm{http://www.lacuarta.com/diario/2006/02/22/22.08.4a.CRO.CIBERLOLA.html}$

${ }^{27}$ En http://www.lacuarta.cl/diario/2006/05/13/13.06.4a.CRO.PORGIL.html 


\subsection{Ejemplos actuales}

a) $B a c a ́ n n^{28}$

El Diccionario del lunfardo indica:

Bacán. Lunf. Hombre, onomásticamente./Concubino, respecto de su mujer. // Persona rica, pudiente. Que vive en abundancia. Femenino: bacana. // Gran señor.// Elegante, pintón.// p. ext. Objeto suntuoso: un reloj bacán.// p. ext. De categoría. Una fiesta bacana.// Estar bacán. Estar a gusto, de lo mejor. Pasarla bien. // Parla Bacana. Conversación fluida, elegante, florida. // Pinta Bacana. Elegancia, buena presencia, apostura (Espíndola, 2002: 45. Las negritas son del autor).

A diferencia, de muchos de los casos anteriores, el DRAE reconoce el uso de esta palabra en el español de Chile (entre otros países):

bacán ${ }^{1}$, na.

1. adj. Chile, Col. y Cuba. En lenguaje juvenil, muy bueno, estupendo, excelente.

2. adj. Chile. Dicho de una persona: Prepotente, sobrada.

3. adj. Chile. Dicho de una persona o de un espectáculo: taquillero.

4. adj. coloq. Col. y Cuba. Dicho de una persona: Muy atractiva. ${ }^{29}$

Dos ejemplos recogidos de la prensa escrita confirman su uso masivo en el español coloquial chileno, principalmente en el segmento juvenil:

- Día del Niño bacán en el Museo Naval ${ }^{30}$

- Presi brasileño juró que nuestro ejército es el más bacán del conti ${ }^{31}$

Resulta interesante que en el DRAE no aparece consignado el uso de esta palabra en Argentina. No obstante, como consta en la cita del Diccionario del lunfardo, su uso es amplio en esta nación.

En cuanto a su origen, el mismo Diccionario del lunfardo señala:

\footnotetext{
${ }^{28}$ Esta palabra en particular ameritaría un detallado análisis sociolingüístico, por lo extensivo de su uso en Chile, particularmente en el lenguaje juvenil. Sin embargo, por razones de espacio nos limitaremos a seguir la estructura que hemos expuesto hasta aquí.

${ }^{29}$ En http://buscon.rae.es/draeI/SrvltConsulta?TIPO_BUS=3\&LEMA=bac\%C3\%A1n html

${ }^{30}$ En http://www.estrellavalpo.cl/prontus4_noticias/site/artic/20090807/pags/20090807001204.

${ }^{31}$ En http://www.lacuarta.cl/contenido/66_61012_9.shtml
} 
Américo Castro en su libro La peculiaridad lingüística rioplatense y su sentido histórico (1941) deriva esta voz del genovés bacan o baccan. José Gobello la remite también al genovés baccan, con el sentido de jefe del lugar (Diccionario lunfardo, 1989). Igualmente, Mario E. Teruggi opina que "parece provenir del vocablo genovés bacan, patrón y, figuradamente, padre o jefe de familia". "De estas acepciones primitivas -agrega- es fácil el pasaje a los derivados de persona acaudalada, sujeto que vive bien y hombre que mantiene a una querida, los tres significados esenciales del lunfardo (....) (Espíndola, 2002: 46).

También es interesante que ya una milonga del año 1926 consigna esta palabra:

Termina la milonga. Las minas retrecheras

Salen con sus bacanes, henchidas de emoción,

Llevando de esperanzas un cielo en sus ojeras

Y un mundo de cariño dentro del corazón. ${ }^{32}$

Decimos que es interesante, porque el uso masivo de esta palabra en el español de Chile es claramente posterior a esta data (no antes de la década de los ochenta).

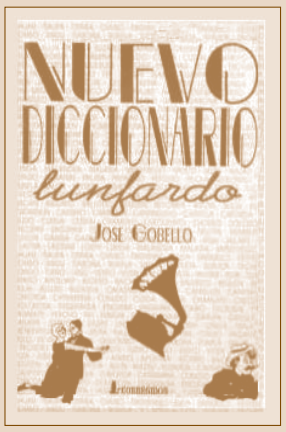
b) Arrugar
El Nuevo diccionario lunfardo indica:

Pop. Apocarse, acobardarse (Gobello, 1999: 24).

Si bien esta palabra está incluida en el DRAE, no se consigna el significado de "acobardarse", ni tampoco su uso en Argentina. Sin embargo, como hemos visto en la cita del Nuevo diccionario lunfardo, en este país su uso es evidente. Mismo caso se presenta en el español coloquial de Chile, como muestran los siguientes ejemplos:

- Kenita arruga con bikinis ${ }^{33}$

- Pampita no va a arrugar bailando ${ }^{34}$

\footnotetext{
32 “Oro muerto (Girón porteño)”. Tango. Julio P. Navarrine, 1926. Citado en Espíndola (2002: 44). Las cursivas son nuestras.

${ }^{33}$ En http://www.terra.cl/entretencion/index.cfm?id_cat=118\&id_reg=1221850

${ }^{34}$ En http://www.cronica.cl/edicion_cronica/seccion/articulo.php?id=38309\&dia=1187409600
} 
En cuanto a su origen, el Nuevo diccionario lunfardo cita el verso "iQue no arrugue el encargado!", de una composición poética argentina del año 1916 (Fernández, 1916: 93; citado en Gobello, 1999: 24), fecha claramente anterior a aquella en que el uso de esta palabra se masifica en Chile (no antes de los años setenta).

c) Bancar

El Diccionario del lunfardo señala:

Bancar. 1. p. Sostener, mantener a alguien económicamente. Estoy bancando a un amigo que está desocupado. // Tolerar, soportar el carácter, la mala forma de ser de alguien. Mi novia es caprichosa, pero yo la banco. // Aguantar una situación desagradable, una mala racha, una enfermedad, etc., sin reacciones negativas, esperando que todo pase. // Afrontar las consecuencias que puede acarrearle a uno mismo su propia manera de ser o de proceder. Mi carácter me trae problemas, pero yo me la banco... (Espíndola, 2002: 51).

La conexión de esta palabra con Argentina (y Uruguay) se consigna también en el DRAE:

\section{bancar.}

1. tr. coloq. Arg. y Ur. Mantener o respaldar a alguien.

2. tr. coloq. Arg. y Ur. Soportar, aguantar a alguien o algo. A ese pesado no lo banca nadie. U. t. c. prnl. No se banca las críticas.

3. tr. Ur. Pagar un gasto colectivo.

4. prnl. coloq. Arg. Responsabilizarse, hacerse cargo de una situación. Yo me banco lo que digo. ${ }^{35}$

Nótese que no se menciona a Chile como país en el cual se usa esta palabra. Sin embargo, los siguientes ejemplos muestran su plena difusión en este país:

- El ministro de Hacienda indicó que los exportadores deben "bancarse" la caída del valor de la divisa, tal como no se quejan cuando les va "estupendamente bien" 36 .

\footnotetext{
${ }^{35}$ En http://buscon.rae.es/draeI/SrvltConsulta?TIPO_BUS=3\&LEMA=bancar

${ }^{36} \mathrm{En} \mathrm{http://www.cooperativa.cl/eyzaguirre-llamo-a-la-sofofa-a-aguantar-el-bajo-precio-del-}$ dolar/prontus_nots/2006-01-02/172741.html
} 
- ... pero cuando activa el seguro y porque la aseguradora es dura para pagar nos tenemos que bancar los llamados ${ }^{37}$.

Esta palabra se comienza a usar en Chile no antes de la década de los noventa; sin embargo, el Nuevo diccionario lunfardo ya en 1981 constata su uso masivo en Argentina.

\section{d) Chanta}

El Diccionario del lunfardo indica:

Regresión de chantapufi. Incumplidor, informal, de poco o ningún crédito [...] Que alardea sin tener de qué [...] (Espíndola, 2002: 120).

El DRAE no consigna esta palabra, no obstante su amplio uso tanto en Argentina como en Chile. En relación con su uso en este último país, son elocuentes los siguientes ejemplos extraídos del diario The Clinic y del website de Canal 13, respectivamente:

- Felipe Camiroaga: ¡Eres un chanta! 38

- Nuevo concurso ciudadano busca el lomo de toro "más chanta"39.

Sobre el origen de esta palabra, el Diccionario del lunfardo indica que está en el genovés:

Del gen. Cianta: impacto de una bocha sobre otra. [...] No pagar un gasto, no compartirlo.//No trabajar. Haraganear (Espíndola, 2002: 120).

Este mismo texto cita a Teruggi (1974): "Como lunfardismo, chantapufi o chanta, han variado algo en su significación, pues denotan un individuo charlatán y jactancioso". Nótese que ya a comienzos de los años setenta esta palabra tiene plena difusión en Argentina. En Chile, en cambio, comienza a popularizarse recién a fines de los noventa.

\footnotetext{
${ }^{37}$ En http://www.reclamos.cl/reclamo/ripley_seguro_de_cesantia_0

${ }^{38}$ En http://www.theclinic.cl/2009/06/08/felipe-camiroaga-\%C2\%A1eres-un-chanta/

${ }^{39} \mathrm{En}$ http://teletrece.canal13.cl/t13/html/Noticias/Chile/325026.html
} 
e) Romper(la)

El Diccionario del lunfardo consigna:

[...] En los deportes en que se juega con pelotas o bochas, se dice cuando un jugador realiza grandes jugadas y se destaca con brillo propio. Maradona la rompió en México contra los ingleses. // [...] (Espíndola, 2002: 437).

El DRAE no consigna este uso entre sus acepciones. Sin embargo, como muestran los siguientes ejemplos, éste es común también hoy en Chile:

- La rebelde Maite Orsini promete romperla en Amor Ciego $2^{40}$

- Don Omar la rompe con su nuevo disco ${ }^{41}$

Es interesante que en un titular del año 1999, en un website cultural argentino, se utiliza esta palabra con la acepción que nos ocupa:

- Octubre Rojo la rompió en Brandsen ${ }^{42}$. El recital de Octubre Rojo hizo arder las pampas.

Decimos que es interesante porque su uso en Chile es rastreable recién a mediados de la década que corre.

f) Trucho

El Diccionario del lunfardo indica:

1. p. Falso. Falsificado, adulterado. De truchar (Espíndola 2002: 484).

El DRAE explicita su difusión en Argentina (y Uruguay):

1. adj. coloq. Arg. y Ur. Falso, fraudulento. Este billete es trucho ${ }^{43}$.

\footnotetext{
${ }^{40}$ En http://enescena.canal13.cl/espectaculos/enescena/html/Television/346328Itplqtv_i_tpl.html

${ }^{41}$ En http://noticias.universia.cl/barrio/disqueria/143304/don-omar-la-rompe-con-su-nuevodisco.html

${ }^{42}$ Brandsen es una ciudad de la Provincia de Buenos Aires.

${ }^{43}$ En http://buscon.rae.es/draeI/SrvltConsulta?TIPO_BUS=3\&LEMA=trucho
} 
Nótese que aquí no se menciona a Chile. Sin embargo, su uso en este país queda de manifiesto con los siguientes titulares de dos diarios regionales:

- Semáforo trucho en San Pedro de la Paz ${ }^{44}$

- Fue un programa trucho $^{45}$

Respecto de la fecha de difusión en Argentina, el Nuevo diccionario lunfardo señala que "Es término difundido en la década de 1980" (Gobello, 1999: 248). En Chile, en cambio, este término se difunde recién a partir de los años noventa.

\section{g) La previa}

Hemos dejado para el final de esta sección esta frase que tiene una difusión reciente en el español de Argentina y recientísima en el de Chile. Con respecto a lo primero, es interesante que su uso no se consigna en los diccionarios de lunfardismos a los que pudimos acceder (el más reciente se publicó en 2002). Sin embargo, su uso en el español hablado en este lustro en este país queda evidenciado con el siguiente ejemplo extraído de un blog argentino dedicado a frases del fútbol:

- La previa, hace 20 años... "Ruggeri, Ruggeri, a quien tenés que marcar vos?.... Ahhhh!!! Rummeeennigueee, ahhhhhhh". Carlos Bilardo molestando al 'Cabezón' a las 4 de la mañana, para ver si tenía la cabeza puesta en la final del 86 contra Alemania... ${ }^{46}$

Es interesante que este posteo está fechado el 26 de junio de 2006, pues, al rastrear el uso de esta palabra en Chile, no registramos ninguna aparición anterior o durante ese $a n ̃ o^{47}$.

Dado que actualmente esta frase tiene amplísima difusión en la jerga del fútbol -en ambos países-, todo parece indicar que se comenzó a usar en los programas deportivos argentinos, desde allí se difundió al léxico deportivo

\footnotetext{
${ }^{44}$ http://www.cronica.cl/cronica_html/site/artic/20090817/pags/20090817081222.html» En http://www.cronica.cl/cronica_html/site/artic/20090817/pags/20090817081222.html

${ }^{45}$ En http://www.mercuriovalpo.cl/prontus4_noticias/site/artic/20080919/pags20080919 000411.html

${ }^{46}$ En http://frasesfutboleras.blogspot.com/2006_06_01_archive.html

${ }^{47} \mathrm{La}$ primera evidencia tiene como data el año 2007.
} 
chileno y, a partir de ahí, se difunde de manera vertiginosa y explosiva al léxico cotidiano chileno. Y no sólo al ámbito deportivo, pues, en la actualidad, esta expresión también se utiliza para referirse a toda instancia de diversión juvenil previa al carrete $^{48}$ central que se realiza después de la medianoche ${ }^{49}$.

\subsection{Permeabilidad transdiastrática y transetaria}

Es indudable que la influencia que una lengua -o variante de una lenguaejerce sobre otra ocurre en un contexto cultural más amplio. No suele ocurrir, en efecto, que una comunidad de habla sea permeable a los giros lingüísticos de otra y esto no se refleje en otro orden de cosas. Por ejemplo, la influencia hispánica en el mapuche es visible no sólo en aspectos estrictamente lingüísticos, sino también en aspectos culturales más amplios, como el retroceso en la práctica de algunas ceremonias tradicionales, el escaso uso de las vestimentas tradicionales, etc. En la vereda opuesta, en el caso de los gitanos, el mantenimiento de "lo rromané" no se limita a la lengua, sino que también se refleja en otros aspectos culturales más amplios, como la práctica de las ceremonias tradicionales (el biau (matrimonio), el bávine (colocación del nombre), la sláva (celebración a la virgen), etc., la vigencia del tribunal tradicional (la kris), el uso de la vestimenta tradicional de las mujeres, entre muchas otras manifestaciones (Salamanca, 2004/2005).

Respecto del tema que nos ocupa, y, por supuesto, guardando las proporciones, consideramos que la permeabilidad que el español de Chile exhibe en relación con el español de Argentina está en consonancia con una permeabilidad cultural más amplia, la cual presenta dos características relevantes: es transdiastrática y transetaria. Con respecto a lo primero, consideremos los siguientes casos:

a. En el estrato sociocultural alto, esta influencia se deja sentir a través de tres vías: la televisión por cable (que, hoy por hoy, ya no es privativa de este estrato, pero lo fue en un comienzo), la presencia masiva de argentinos en la

\footnotetext{
${ }^{48}$ En el léxico del español de Chile, carrete designa a una instancia de diversión colectiva juvenil donde suele abundar el alcohol.

${ }^{49}$ Hoy en día, incluso, hay pubs, minimarkets, programas radiales, etc., que llevan por nombre "la previa".
} 
zona central de nuestro país durante sus vacaciones y la mayor facilidad que tienen los chilenos para viajar a Argentina en los últimos años ${ }^{50}$.

Respecto del primer punto, resulta interesante observar la potente influencia que los relatores deportivos argentinos han ejercido sobre los relatores chilenos, no sólo en el estilo mismo del relato, sino en la jerga que utilizan. Expresiones como la previa, de una, al toque, etc., se acuñan en el léxico deportivo argentino -especialmente el futbolístico-y, ya sea por exposición directa o vía relatores chilenos, se difunden en el léxico del español de Chile ${ }^{51}$.

Respecto del segundo punto, resulta interesante observar que una cantidad importante de argentinos viaja de vacaciones durante los meses de verano a la zona norte y central de nuestro país; específicamente, los balnearios de la IV y V regiones de nuestro país. Así, las playas, pubs, discoteques, etc., se convierten en centros de interacción lingüística e irradiación de léxico proveniente del otro lado de los Andes $^{52}$.

Como contrapartida, uno de los destinos preferidos de los chilenos de las clases media y media-alta en el extranjero es Argentina ${ }^{53}$. Esto es relevante si se sitúa en el contexto, enunciado en 2, de la facilidad que tiene el chileno para asimilar la variedad de habla del país en que se encuentra (aunque esta característica es menos evidente en los sectores de mayores ingresos). En palabras de Sáez:

En Chile vivimos un proceso de globalización y de internacionalización de todo tipo: economía, comunicaciones, viajes. Cada vez llegan más extranjeros a nuestro país y un tercio de los chilenos viaja al exterior, gracias a un evidente mejoramiento de nuestro estándar de vida (Sáez, 1999: 18).

b. En el otro extremo, en el estrato sociocultural bajo, también se percibe la influencia de "lo argentino". Uno de los aspectos donde es más reconocible

\footnotetext{
${ }^{50}$ En la mayoría de los casos, viajes turísticos habituales, en el caso de los adultos; y viajes de estudios de fin de año, en el caso de los niños y jóvenes.

${ }^{51}$ Hay que destacar la importancia que tiene el ámbito futbolístico en la cultura de ambos países.

${ }^{52}$ Según Sernatur, la afluencia de turistas argentinos entre los meses de enero y marzo de 2009 fue de 363.563 visitantes (http://www.sernatur.cl/institucional/scripts/industria01.php).

${ }^{53}$ Sernatur consigna la cifra total, no despreciable, de 1.462 .083 chilenos que viajaron a este país durante 2008 .
} 
tal influencia es en el impacto que en los últimos años ha tenido en Chile la música de las villas miseria del país transandino (la "cumbia villera"). Esto se observa, por ejemplo, en la cantidad de discos que se venden y ruedan en radios muy populares de nuestro país, y en la popularidad que han adquirido algunos grupos musicales y solistas transandinos en Chile. Estos grupos y solistas, en efecto, se han constituido en referentes de toda una corriente musical muy popular en los sectores medios-bajos y bajos de nuestro país como es la música sound.

En este punto resulta interesante observar cómo a través de uno de estos grupos ("Los Sultanes") se introduce una nueva palabra en el léxico chileno: chabón. En la primera estrofa de la canción "Estoy saliendo con un chabón", de este grupo, leemos:

Estoy saliendo con un chabón, Ya más de un año van casi dos Estoy enamorado y saben que Me gustaría darle un varón

Dado que quien interpreta esta canción es un hombre con voz y ademanes afeminados ${ }^{54}$, en Chile se asoció el término chabón con homosexual; no obstante tener en el español de Argentina sólo el significado de muchacho joven.

Ahora, es cierto que la frecuencia con que ingresa una palabra o expresión más compleja de una lengua -o dialecto de una lengua- a otra por esta vía es más bien escasa, pero, como se ve, no imposible. Lo que sí es claro, es que la exposición a este léxico musical a lo menos refuerza el ingreso que paralelamente se produce por otras vías. Pensemos, por ejemplo, en palabras como aguante, que está ampliamente difundida en Argentina -especialmente en el léxico futbolístico- y que en Chile ya se ha comenzado a utilizar y a escuchar frecuentemente a través de una cumbia villera interpretada por el grupo "Yerba Brava":

$\mathrm{Al}$ equipo que tiene más aguante

Lo llevo dentro del corazón....

Saltando, cantando, prendidos en el trapo

Dejamos el alma en el tablón.

\footnotetext{
${ }^{54}$ Ver http://www.youtube.com/watch?v=7xH6ficYsFs
} 


\section{c) Clase media y alcance transdiastrático}

Los casos anteriores muestran aspectos de la influencia de lo argentino en dos segmentos extremos de la población chilena. Sin embargo, tal influencia también se puede percibir en los sectores que podrían ser catalogados de clase media o en la sociedad chilena en su conjunto.

Por ejemplo, hoy no constituye ningún escándalo que los futbolistas chilenos entren o salgan del campo de juego dándose un beso en la mejilla, lo cual hasta hace unos años era reprobado y, con razón, descrito como una costumbre típica del futbolista argentino.

En el plano de la gestualidad, por su parte, hoy en día en Chile se puede observar a personas que evidencian una actitud de sorpresa a través de un gesto que consiste en juntar los dedos de cada mano, contra el pulgar, y dirigirlos hacia el rostro propio, realizando de dos a tres movimientos rápidos de abajo hacia arriba, gestualidad que se puede verbalizar con expresiones como "y esto qué significa", "y éste qué pretende", etc. Claramente, este ademán es una réplica del gesto que ya, desde hace bastante tiempo, es parte del inventario gestual en Argentina.

Por otro lado, si pensamos en la capacidad de penetración de los medios de comunicación masiva -especialmente la televisión (presente en prácticamente todos los hogares chilenos) - podemos ver que también se produce una influencia del país transandino. A modo de ejemplo, programas como "CQC" "Intrusos", etc., que se exhiben actualmente en Chile, constituyen calcos de los correspondientes programas argentinos con idéntico nombre.

En esta misma dirección, es interesante constatar que los programas más vistos últimamente en la televisión chilena, aquellos del género realities, casi sin excepción han tenido entre sus participantes a personas de nacionalidad argentina, lo que revela que para quienes miden lo que el público chileno considera "bueno" o "malo", televisivamente hablando, lo argentino es atractivo y prestigioso. No parece un despropósito pensar, en consecuencia, que la interacción entre personas que hablan un dialecto permeable, como el chileno, con personas que hablan un dialecto poco permeable, como el argentino, implicará alguna mella en el primero, lo cual será visto, procesado $\mathrm{y}$-eventualmente- asimilado por una cantidad significativa de telespectadores.

Con respecto a la permeabilidad transetaria, resulta interesante considerar un reportaje del diario La Tercera del 19 de abril de 2009, que se refiere a la entrada desde Argentina de una nueva tribu urbana, la cual se comienza a difundir entre los adolescentes de estrato alto de Chile: 
Floggers: la popular tribu urbana argentina desembarcó en Chile. Lo primero que sus amigas le contaron a Alejandra (15) luego de volver de un viaje a Buenos Aires la dejó boquiabierta: "Hay una nueva moda en Argentina", le dijeron. Grandes lentes de sol, pantalones pitillos y peinados desordenados. Se trataba de los floggers, la tribu urbana que hoy inunda los malls de Argentina y que algunos adolescentes chilenos están decidiendo seguir.

La motivación de los jóvenes chilenos que llegaron a este movimiento es común: diferenciarse de las tribus urbanas que actualmente plagan nuestro país, sobre todo de los pokemones, con quienes se les suele confundir.

Catalina, quien decidió seguir la tendencia después de verla en sus amigos argentinos, asegura que una de sus actividades favoritas, como buena flogger, es comprar ropa. "Me gusta comprarme poleras. Tener harta ropa para variar”, explica.

"Los floggers son criticados en Argentina, porque son medio cuicos. Los critican los cumbieros", explica Catalina, refiriéndose a los jóvenes que siguen la cumbia villera. Y asegura que acá en Chile pasa algo similar. "Los floggers son como más peloláis". Pero eso no detiene la estampida: "Acá está recién empezando, pero creo que cada vez más niños van a querer ser floggers" 55 .

Esto resulta interesante, pues se aprecia claramente que la permeabilidad respecto de aspectos culturales y lingüísticos provenientes de Argentina no es exclusiva de la población adulta, sino que también incluye al segmento más joven de nuestro país. Esto, valga el argentinismo, no es menor, si consideramos, con Sáez (1999: 20), que "El lenguaje juvenil ha alcanzado un estatus y una difusión que no había tenido antes” y, más importante aún, impone una suerte de norma a seguir.

\section{TÉRMINOS QUE PASAN PIOLA}

Una de las características más notable de la incorporación de argentinismos al español de Chile es su imperceptibilidad, esto es, se usan con total naturalidad en el español de Chile y, en general, no existe consciencia en los hablantes de su origen transandino. Así, por ejemplo, respecto de la mayoría de los ejemplos que aquí hemos presentado, los chilenohablantes ignoran su origen o consideran que son una innovación "nacida y criada" en el español de Chile.

\footnotetext{
${ }^{55}$ En http://latercera.com/contenido/741_120425_9.shtml
} 
Presentamos dos textos que hemos construido y que contienen palabras o expresiones cuyo origen podría ser situado con alto grado de certeza sociolingüística en la República Argentina. Veremos que dichas expresiones fluyen con total naturalidad y podrían atribuirse, perfectamente, a dos chilenos: el primero, un político que arenga a un grupo de jóvenes; el segundo, un joven que da un testimonio a un grupo de amigos, respectivamente:

\section{Texto 1}

Después de bancarnos años difíciles, llegó la hora de romperla. Porque sí $o$ sí hay que derrotar el subdesarrollo. Y hay que hacerlo de una, al toque, sin arrugar.

No debemos escuchar argumentos contrarios chantas, sino que debemos estar prendidos con la idea de que podemos ir por más y hacer realidad, como dirían ustedes los jóvenes, un proyecto bacán.

Aquí no hay lugar para chamullentos, ni es el tiempo de engrupir ni bartolear. Es el tiempo de jugársela.

Chicos, puede ocurrir que nos basureen y nos traten de locos; ¿locos? sí, pero locos lindos.

Chicos, este desafío no es menor, pues si no lo hacemos, todo seguirá siendo un desastre.

Aguante jóvenes! Pintémosle la cara al subdesarrollo. Aguante, jóvenes, que vamos por más!

Chau!

\section{Texto 2}

Te cuento:

Estábamos en la previa, preparándonos para ir al cumple del Fer, cuando apareció el tipo. Reconozco que tenía buena facha: era canchero, entrador, pero venía con ganas de engrupirse a mi mina.

Por supuesto, me calenté y en la bronca me porté como punga.

Estoy arrepentido, pero bueno, por ahí las cosas no siempre salen como uno las pensó.

En fin. Ya fue. Lo hecho, hecho está.

\section{CONCLUSIONES}

Como hemos señalado, uno de los aspectos que destaca de esta permeabilidad asimétrica es su dinamismo, pues afecta los distintos niveles sociales, 
los distintos grupos etarios y tiene una tradición histórica. Al mismo tiempo, es interesante que este proceso se produce sin un mayor grado de conciencia entre los hablantes del español de Chile, lo cual implica que el hablante de nuestra variante, salvo casos muy específicos, estima que parte importante del léxico que proviene del país transandino es "nuestro".

Conviene destacar, además, que los ejemplos dados hasta aquí en absoluto agotan los casos en que es posible rastrear la influencia que nos ocupa. En efecto, sería interesante analizar la conexión que existe entre la tendencia a apocopar que existe actualmente en el español de Chile (pensemos en palabras y frases como "finde", "peli", "la Fran", "el Fer", el/la "Agus") y la difusión de este fenómeno en Argentina. También se debe analizar exhaustivamente la tendencia a la pérdida del pretérito imperfecto de subjuntivo, el cual en la última década tiende a ser reemplazado por el tiempo presente de ese mismo modo verbal (como en "me dijo que compre un auto" por "me dijo que comprara un libro"). Otro foco de exploración debe ser el ámbito deportivo, particularmente el futbolístico, pues, como hemos dicho, constituye una cantera muy productiva para un trabajo como el presentamos.

Por otro lado, si se compara la influencia de otras variantes del español con la presencia de argentinismos en el español de Chile, se aprecia una realidad cualitativa y cuantitativamente distinta. Por ejemplo, es posible advertir en nuestro léxico algunos mexicanismos -como el adjetivo "menso", y las expresiones "me da cosa" y "vaya a cantarle a su abuela", entro otros-, los cuales ingresaron fundamentalmente a través de los programas infantiles "El Chavo del Ocho" y "El Chapulín Colorado". Sin embargo, la distancia geográfica con ese país -y, en consecuencia, las pocas posibilidades de interacciones fluidas entre ambas variantes- y el no ostentar el dialecto mexicano un grado sobresaliente de prestigio en Chile hacen altamente improbable que esa variante dialectal influya de manera importante en el español de Chile.

En este contexto, los dialectos hablados en los países fronterizos constituyen de suyo variantes que, en términos de probabilidades, se pueden transformar en agentes de influencia más decisiva en otra variante. Para el caso que nos ocupa, ni el español hablado en Perú, ni el español hablado en Bolivia constituyen variedades prestigiosas para el chilenohablante, lo que marca una diferencia importante con el español hablado en Argentina. En efecto, tal como hemos dicho, esta última variedad del español permea al español de Chile en (macro)variables fundamentales (diastrática y diafásica), su influencia no se restringe a un léxico especializado, y pasa prácticamente inadvertida para el chilenohablante. 
No es improbable, en consecuencia, que esta tendencia se consolide y, de mantenerse un estado de cosas similar al que tenemos en la actualidad, se proyecte a otros planos de la lengua (plano fónico y morfosintáctico). Hay indicios que permiten visualizar lo señalado. Por ejemplo, la incipiente difusión de "sos" -en reemplazo de "eres" o erís-, como se observa en ciertos posteos actuales en el chat ("sos un amor", "sos pesado", etc. son expresiones que se comienzan a leer con cada vez mayor frecuencia en este popularísimo medio de interacción). Por supuesto, como todo proceso de evolución lingüística, esto no se produce de la noche a la mañana, pero el prestigio encubierto que existe respecto de la variante hablada en Argentina y la permeabilidad asimétrica que se configura entre ambas variantes del español hacen plausible esta hipótesis.

Por último, estimamos que estas reflexiones deberán ser evaluadas por su consistencia interna, plausibilidad y coherencia y no por su sujeción a un sofisticado aparataje estadístico, pues no emanan de un clásico estudio experimental. En consecuencia, corresponderá a sociólogos, historiadores o sociolingüistas determinar su pertinencia, y a las futuras generaciones constatar si las hipótesis aquí planteadas iban en la dirección correcta.

\section{REFERENCIAS}

Espíndola, Athos. 2002. Diccionario del lunfardo. Buenos Aires: Planeta.

Fernández. Felipe. 1916. Versos rantifusos. Buenos Aires. Citado en Gobello (1999).

Gobello, José. 1999. Nuevo diccionario lunfardo. Buenos Aires: Corregidor.

Lugones, Benigno. "Los beduinos urbanos", en La Nación, 18 de marzo de 1879, Buenos Aires.

Real Academia Española de la Lengua. 2009. Diccionario. Versión on line disponible en $<$ http://www.rae.esl $>$.

Riquelme, Jorge y Gonzalo Alarcón. 2008. "El peso de la historia en la inmigración peruana en Chile", en Polis Vol. 7, № 20, pp. 299-310.

Sáez, Leopoldo. 1999. El español de Chile en las postrimerías del siglo XX. Santiago: Universidad de Santiago.

Salamanca, Gastón. 2004/2005. "Vitalidad lingüística y cultural en un mundo globalizado: El caso rromané, frente a las lenguas vernáculas chilenas", en Sociedad Hoy No 8-9, pp. 107-116.

Salamanca, Gastón y Valverde, Ana. 2009. "Prestigio y estigmatización en variantes anteriorizadas y posteriorizadas de las vocales del español de Chile", en Literatura y Lingüística № 20, pp. 125-140.

Salas, Adalberto. 1992. El mapuche o araucano. Fonología. Gramática y antología de cuentos. Madrid: MAPFRE. 
1996. "Aymara mapuche ¿lenguas o dialectos? En torno a la valoración social de los vernáculos chilenos”, en Atenea No 473, pp. 25-37.

Silva-Corvalán. 2001. Sociolingüística y pragmática del español. Washington D.C.: Georgetown University Press.

Valdivieso, Humberto. 1983. "Prestigio y estigmatización: factor determinante en la enseñanza institucionalizada de la lengua materna”, en RLA. Revista de Lingüística Teórica y Aplicada N²1, pp. 137-142.

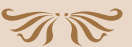

